\title{
Effect of Yoga on Balance in Geriatric Population
}

\author{
Krishna Ketan Patel, PT ${ }^{1}$, Dr. Mayura Deshmukh, (PT) ${ }^{2}$, Dr. Tushar Palekar, PhD. ${ }^{3}$ \\ ${ }^{1}$ Dr. D. Y. Patil College of Physiotherapy, Pune, Maharashtra, India. \\ ${ }^{2}$ Assistant Professor, Cardiopulmonary Depatrment, Dr. D. Y. Patil College of Physiotherapy, Pune, \\ Maharashtra, India \\ 3Principal, Dr. D. Y. Patil College of Physiotherapy, Pune, Maharashtra, India.
}

\section{ABSTRACT}

Background : The geriatric population is defined as population aged 60 years and above. ${ }^{(1)}$ During this age many of the systems undergo deterioration. Balance problems in elderly are most commonly due to multi factorial condition which may include age related or disease-related declines in the balance system. Research shows that altered balance is the greatest collaborator towards falls in the elderly with a high correlation between balance deficit and the incidence of falls. Iyengar yoga, one of the active, or Hatha, yoga techniques, is a system for developing physical and mental well-being through stretching of all muscle groups for strength, flexibility, and physical balance. Yoga as a complementary therapy is thought to be more therapeutic than traditional exercise because it involves active engagement between mind and body. Its practice has been associated with increased muscle strength, endurance, flexibility, range of motion and cardiopulmonary endurance. It mainly works on increasing body awareness and proprioception, which will lead to improvement of balance in older adults.

\section{Objectives:}

1. To compare pre and post score of Modified Clinical Test of Sensory Interaction in Balance (CTSIB-M).

2. To compare pre and post score of Time up and go test.

\section{Materials and Methodology:}

This was an experimental study that included 40 participants, healthy older adults between the age group 60-75 years, both male and female. The subjects were randomly divided in to 2 groups; Group A was the experimental group whereas group B was the control group.

The experimental group was made to perform yogasanas for the duration of four weeks for 5 times a week whereas the control group was not given any intervention.

\section{Result and Conclusion:}

The study conducted concludes that yogasanas are effective in improving balance in elderly individuals at the end of four weeks compared to control group. Thus, it can be used clinically to improve balance in geriatric population.

Keywords : Balance, Yoga, Old Age.

\section{INTRODUCTION}

The geriatric population is defined as population aged 60 years and above. ${ }^{(1)}$ During this age many of the systems undergo deterioration. This has the potential to affect balance, restrict safe mobility, increase the likelihood of a fall and adversely affect quality of life. (2) Balance problems in elderly are 
most commonly due to multi factorial condition which may include age related or disease-related declines in the balance system. Causes of reduced balance in elderly could be weakness in the core stabilizing muscles, altered muscle activation patterns, loss of proprioception, and an inability to control normal postural sway. ${ }^{(3)}$

Balance problems and falls are leading cause of institutionalization in this group. There are numerous risk factors for falling in this population, such as muscle weakness, past history of falls, gait, balance, visual and cognitive impairment, osteoarthritis, depression and so on. ${ }^{(4)}$ Falls among the elderly are associated with high morbidity and mortality and can involve high-cost medical intervention. ${ }^{(5)}$ Research shows that altered balance is the greatest collaborator towards falls in the elderly with a high correlation between balance deficit and the incidence of falls. ${ }^{(6)}$

Age-related changes in the sensorimotor and neuromuscular system negatively affect performance in static and dynamic postural control even in healthy older adults which leads to increased risk of falls. ${ }^{(7)}$ Normal ageing is characterised by a decrease in bone and muscle mass and an increase in adiposity. ${ }^{(8)} \mathrm{A}$ decline in muscle mass and a reduction in muscle strength lead to risk of fractures, frailty, reduction in the quality of life and loss of independence. These changes in musculoskeletal system reflect the ageing process as well as consequences of a reduced physical activity. The muscle wasting in frail older persons is termed 'sarcopaenia'. This disorder leads to a higher incidence of falls and fractures and a functional decline. ${ }^{(9)}$

Skeletal muscle strength (force-generating capacity) also gets reduced with ageing. ${ }^{(9)}$ This reduction in muscle strength causes problems in physical mobility and activity of daily living. The total amount of muscle fibres is decreased due to a depressed productive capacity of cells to produce protein. There is a decrease in the size of muscle cells, fibres and tissues along with the total loss of muscle power, muscle bulk and muscle strength of all major muscle groups like deltoids, biceps, triceps, hamstrings, gastrocnemius (calf muscle), and so on. ${ }^{(10)}$

With ageing, toxins and chemicals build up within the body and tissues. As a whole, this damages the integrity of muscle cells. Physical activity also decreases with age, due to a change in lifestyle. Somehow, the physiological changes of the muscles are aggravated by age-related neurological changes. Most of the muscular activities become less efficient and less responsive with ageing as a result of a decrease in the nervous activity and nerve conduction. (11) Also with ageing, the total water content of the tissue decreases and loss of hydration also adds to the inelasticity and stiffness. ${ }^{(12)}$

Iyengar yoga, one of the active, or Hatha, yoga techniques, is a system for developing physical and mental well-being through stretching of all muscle groups for strength, flexibility, and physical balance. ${ }^{(13)} \mathrm{A}$ person assumes a series of stationary positions that use isometric contraction and relaxation of different muscle groups to create specific body alignments. There is also a deep relaxation component. Yoga as a complementary therapy is thought to be more therapeutic than traditional exercise because it involves active engagement between mind and body. Its practice has been associated with increased muscle strength, endurance, flexibility, range of motion and cardiopulmonary endurance. It mainly works on increasing body awareness and proprioception, which will lead to improvement of balance in older adults. ${ }^{(14,15)}$ 
The geriatric population is defined as population aged 60 years and above. ${ }^{(1)}$ During this age many of the systems undergo deterioration. This has the potential to affect balance, restrict safe mobility, increase the likelihood of a fall and adversely affect quality of life. (2) Balance problems in elderly are most commonly due to multi factorial condition which may include age related or disease-related declines in the balance system. Causes of reduced balance in elderly could be weakness in the core stabilizing muscles, altered muscle activation patterns, loss of proprioception, and an inability to control normal postural sway. ${ }^{(3)}$

Balance problems and falls are leading cause of institutionalization in this group. There are numerous risk factors for falling in this population, such as muscle weakness, past history of falls, gait, balance, visual and cognitive impairment, osteoarthritis, depression and so on. ${ }^{(4)}$ Falls among the elderly are associated with high morbidity and mortality and can involve high-cost medical intervention. ${ }^{(5)}$ Research shows that altered balance is the greatest collaborator towards falls in the elderly with a high correlation between balance deficit and the incidence of falls. ${ }^{(6)}$

Age-related changes in the sensorimotor and neuromuscular system negatively affect performance in static and dynamic postural control even in healthy older adults which leads to increased risk of falls. ${ }^{(7)}$ Normal ageing is characterised by a decrease in bone and muscle mass and an increase in adiposity. ${ }^{(8)} \mathrm{A}$ decline in muscle mass and a reduction in muscle strength lead to risk of fractures, frailty, reduction in the quality of life and loss of independence. These changes in musculoskeletal system reflect the ageing process as well as consequences of a reduced physical activity. The muscle wasting in frail older persons is termed 'sarcopaenia'. This disorder leads to a higher incidence of falls and fractures and a functional decline. ${ }^{(9)}$

Skeletal muscle strength (force-generating capacity) also gets reduced with ageing. ${ }^{\left({ }^{9}\right)}$ This reduction in muscle strength causes problems in physical mobility and activity of daily living. The total amount of muscle fibres is decreased due to a depressed productive capacity of cells to produce protein. There is a decrease in the size of muscle cells, fibres and tissues along with the total loss of muscle power, muscle bulk and muscle strength of all major muscle groups like deltoids, biceps, triceps, hamstrings, gastrocnemius (calf muscle), and so on. ${ }^{(10)}$

With ageing, toxins and chemicals build up within the body and tissues. As a whole, this damages the integrity of muscle cells. Physical activity also decreases with age, due to a change in lifestyle. Somehow, the physiological changes of the muscles are aggravated by age-related neurological changes. Most of the muscular activities become less efficient and less responsive with ageing as a result of a decrease in the nervous activity and nerve conduction. (11) Also with ageing, the total water content of the tissue decreases and loss of hydration also adds to the inelasticity and stiffness. ${ }^{(12)}$

Iyengar yoga, one of the active, or Hatha, yoga techniques, is a system for developing physical and mental well-being through stretching of all muscle groups for strength, flexibility, and physical balance. ${ }^{(13)} \mathrm{A}$ person assumes a series of stationary positions that use isometric contraction and relaxation of different muscle groups to create specific body alignments. There is also a deep relaxation component. Yoga as a complementary therapy is thought to be more therapeutic than traditional exercise because it involves active engagement between mind and body. Its practice has been associated with increased muscle strength, 
endurance, flexibility, range of motion and cardiopulmonary endurance. It mainly works on increasing body awareness and proprioception, which will lead to improvement of balance in older adults. ${ }^{(14,15)}$

\section{MATERIALS AND METHODOLOGY}

Study location: Study was conducted at Rock Garden, Pimpri, Pune.

Sampling method: Simple random sampling method was used. 40 healthy older adults between the age group 60-75 years, both male and female, Subjects who are willing to participate in the study, Subjects who are ready to sign written informed consent form, and Subjects who are functionally independent that is, score of 100 point on barthel index. Subjects having history of any recent musculoskeletal problems, serious cardiac and pulmonary condition which may required hospitalization, neurological conditions, psychiatric illness, serious visual impairments (i.e. cataracts), self-report of uncontrollable diabetes \& hypertension, vertigo, who are already in another active research study were excluded.

\section{Procedure and Data collection:}

After approval from the ethical committee the project was conducted. All subjects were explained about the aim and nature of the study and those willing to participate were requested to sign the consent form. Pre participation evaluation form consisting of general assessment and outcome measures that include Modified Clinical Test of Sensory Interaction in Balance (CTSIB-M), Timed Up and GO test (TUG) were documented. All the subjects were then equally divided into two groups by randomisation method. Group A was the experimental group whereas group $\mathrm{B}$ was the control group. The experimental group was made to perform yogasanas for the duration of four weeks for 5 times a week whereas the control group was not given any intervention.Each therapy session started with 5-10 minutes of warm up focused on slow dynamic muscle movements with shoulder/arm circling, wrist circling and neck rolling.This was followed by $25-30$ minutes of asanas consisting of following poses: Week 1 - Modified Sun salutations on chair,Core strengthener and leg lifts on chair, Knee to chest pose on chair

Week 2 - Tadasana (mountain pose) with chair support, Adho mukho svanasana (downward dog pose) with chair support, Virabhadrasana (warrior pose) with chair support, Utkatasana (chair pose) with chair support

Week 3 - Tadasana (mountain pose), Adho mukho svanasana (downward dog pose), Virabhadrasana (warrior pose), Utkatasana (chair pose), Vrikshasana (tree pose) with chair support, Trikonasana (triangle pose) with chair support

Week 4 -Vrikshasana (tree pose),Trikonasana (triangle pose)

Each asana was performed for 5 times for duration of 10 seconds.

Each therapy session ended with eye yoga and pranayama. Entire session of yoga was under supervision of physiotherapist.

The outcome measures were taken before and after four weeks in both the groups.

For the equally distributed data, inter-group significance was calculated by using Unpaired t- test and intra-group significance was calculated using paired t-test.

\section{RESULTS AND DISCUSSION}

In this study 40 subjects were included and divided into group A and group B randomly and Modified Clinical Test of Sensory Interaction in Balance (CTSIB-M), Timed Up and GO test (TUG) was recorded before and after the intervention and then were compared and graphically represented 
Table 1: Gender Distribution Among Group A And B

\begin{tabular}{|c|c|c|}
\hline GENDER & GROUP A & GROUP B \\
\hline MALE & 10 & 11 \\
\hline FEMALE & 8 & 9 \\
\hline
\end{tabular}

Graph 1 : Graphical Representation of Gender Distribution Among Group A And B

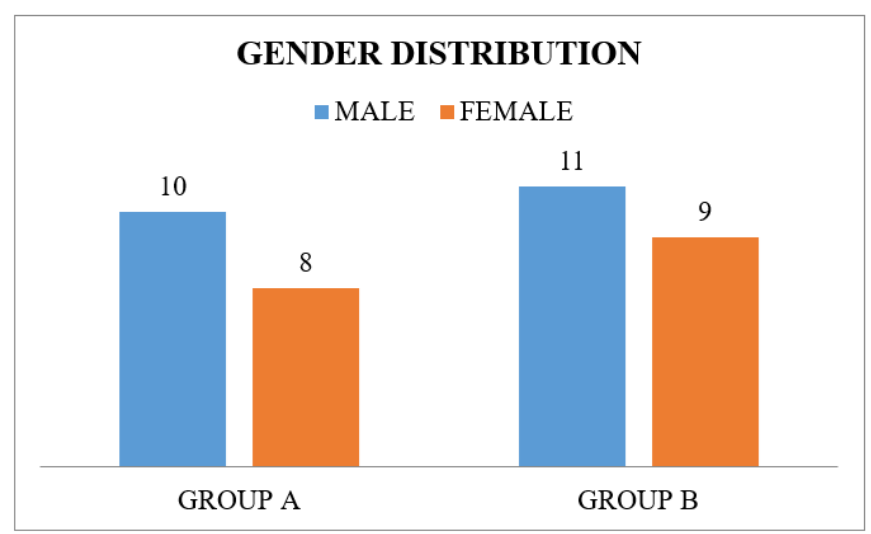

\section{INTERPRETATION:}

It can be inferred from the above data that there were 10 male and 8 female subjects in Group A and 11 male and 9 female subjects in Group B
Table 2 : Age Distribution Among Group A and B

\begin{tabular}{|c|c|c|}
\hline & $\begin{array}{c}\text { MEAN AGE } \\
\text { (years) }\end{array}$ & SD \\
\hline $\begin{array}{c}\text { GROUP } \\
\text { A }\end{array}$ & 65.15 & \pm 4.2 \\
\hline $\begin{array}{c}\text { GROUP } \\
\text { B }\end{array}$ & 67.75 & \pm 5.7 \\
\hline
\end{tabular}

Table 2 : Graphical Representation of Age Distribution Among Group A And B

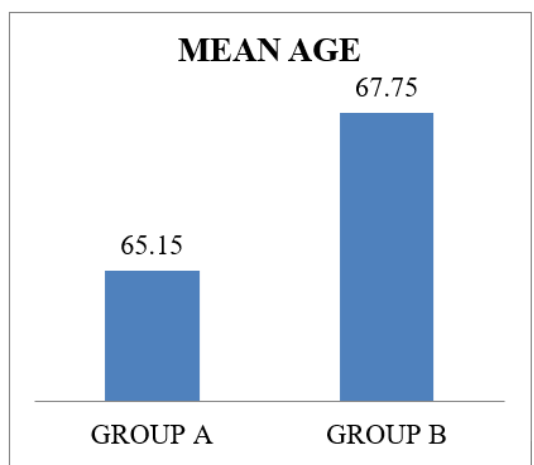

\section{INTERPRETATION:}

It can be inferred from the above data the that the mean age of subjects in Group $A$ is $65.15 \pm 4.2$ years whereas the mean age of subjects in Group B is $67.75 \pm 5.7$ years.

Table 3: Comparison of Pre And Post Values of Time Up and go Test Among Group A and Group B

\begin{tabular}{|c|c|c|c|c|c|c|}
\hline $\begin{array}{c}\text { TUG TEST } \\
\text { (seconds) }\end{array}$ & \multicolumn{2}{|c|}{ PRE } & \multicolumn{2}{c|}{ POST } & SIGNIFICANCE & INFERENCE \\
\hline & MEAN & SD & MEAN & SD & P VALUE & \\
\hline GROUP A & 11.36 & 1.92 & 10.63 & 1.85 & 0.003 & $\begin{array}{c}\text { HIGHLY } \\
\text { SIGNIFICANT }\end{array}$ \\
\hline GROUP B & 11.55 & 2.03 & 11.66 & 2.03 & 0.029 & $\begin{array}{c}\text { HIGHLY } \\
\text { SIGNIFICANT }\end{array}$ \\
\hline
\end{tabular}


GRAPH 3 : Group A V/S Group B Pre And Post Tug Test Scores

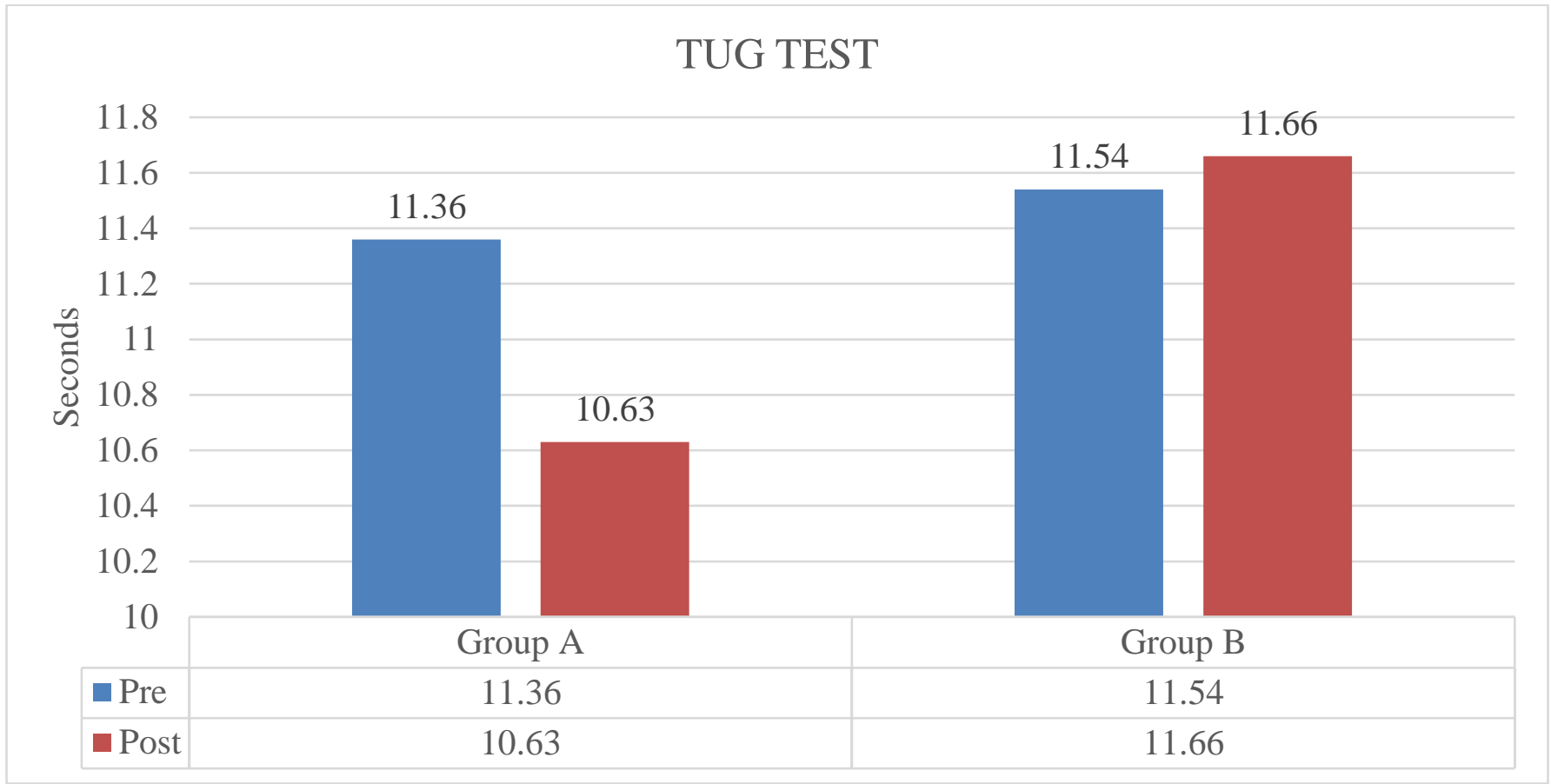

\section{INTERPRETATION:}

According to the above data there was a highly significant decrease (p value $<0.05$ ) in TUG Test scores among Group A whereas there was a significant increase ( $p$ value $<0.05$ ) in TUG Test scores among Group B.

Table 4: Comparison of Pre And Post Values of CTSIB-M Among Group A and Group B

\begin{tabular}{|c|c|c|c|c|c|c|}
\hline $\begin{array}{c}\text { CTSIB-M TEST } \\
\text { (seconds) }\end{array}$ & \multicolumn{2}{|c|}{ PRE } & \multicolumn{2}{c|}{ POST } & SIGNIFICANCE & INFERENCE \\
\hline & MEAN & SD & MEAN & SD & P VALUE & \\
\hline GROUP A & 109.4 & 12.88 & 115.3 & 7.6 & 0.009 & $\begin{array}{c}\text { HIGHLY } \\
\text { SIGNIFICANT }\end{array}$ \\
\hline GROUP B & 115.31 & 6.22 & 114.85 & 5.84 & 0.191 & $\begin{array}{c}\text { SIGNIFICANT } \\
\text { SIGITICAN }\end{array}$ \\
\hline
\end{tabular}


Graph 4 : Group A V/S Group B Pre and Post CTSIB-M Test Scores

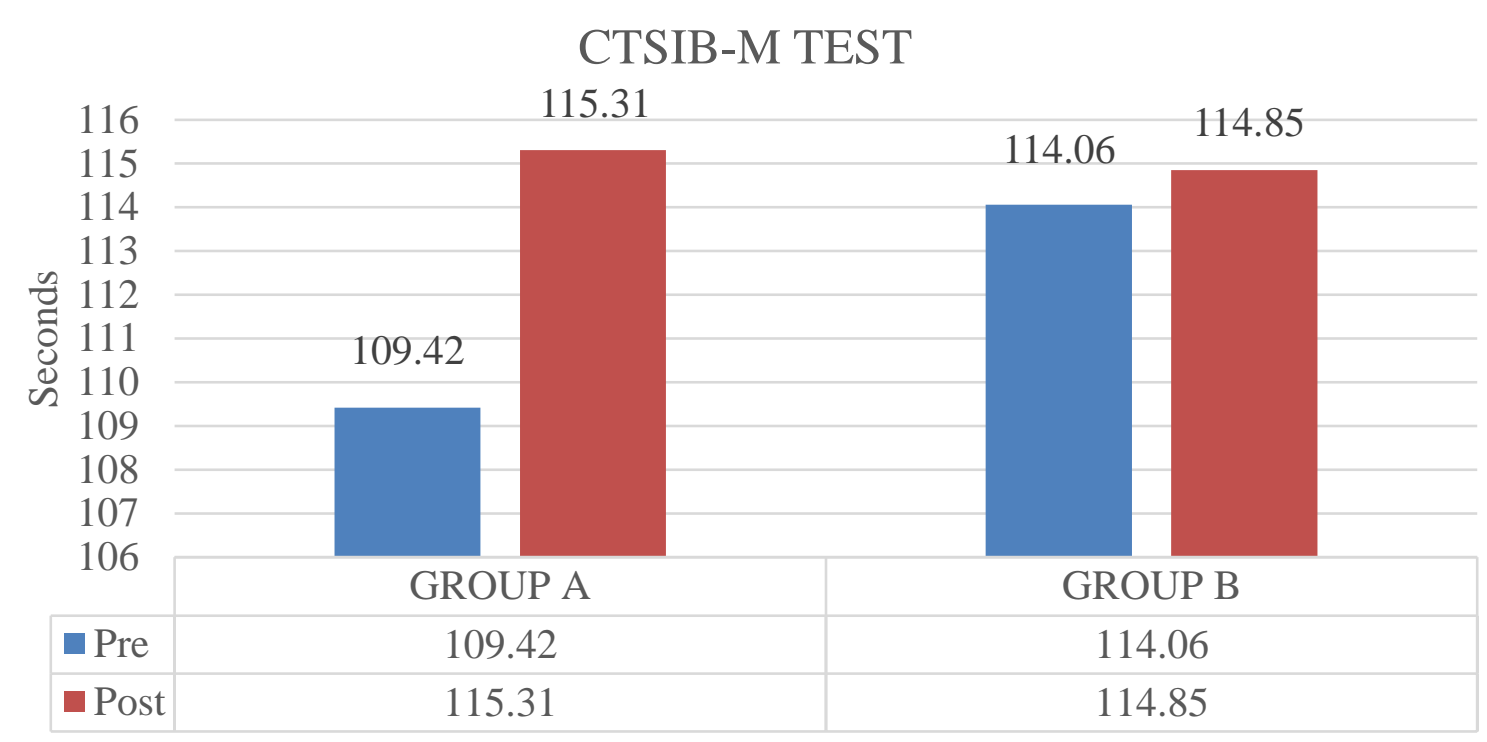

INTERPRETATION:

According to the above data there was a highly significant change ( $\mathrm{p}$ value $<0.05$ ) in CTSIB-M scores among Group A whereas there was a no significant change ( $p$ value > 0.05) in CTSIB-M scores among Group B.

Table 5: Mean Difference of Tug Test Scores Among Group A And Group B

\begin{tabular}{|c|c|c|c|c|c|}
\hline \multicolumn{5}{|c|}{ TUG TEST } \\
\hline \multicolumn{2}{|c|}{ GROUP A } & \multicolumn{2}{|c|}{ GROUP B } & SIGNIFICANCE & INFERENCE \\
\hline $\begin{array}{c}\text { MEAN } \\
\text { DIFFERENCE }\end{array}$ & SD & $\begin{array}{c}\text { MEAN } \\
\text { DIFFERENCE }\end{array}$ & SD & P VALUE & \\
\hline 0.73 & 0.89 & -0.12 & 0.22 & 0.000 & $\begin{array}{c}\text { HIGHLY } \\
\text { SIGNIFICANT }\end{array}$ \\
\hline
\end{tabular}

Graph 5: Group A V/S Group B Mean Difference of Tug Test Scores

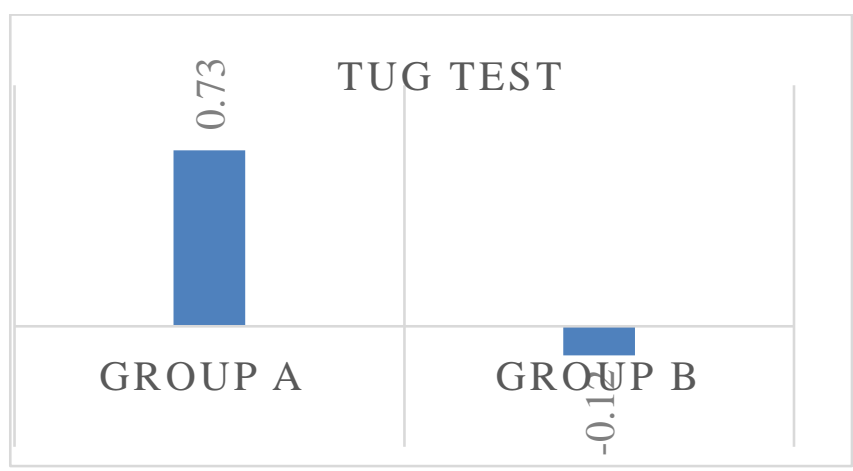




\section{INTERPRETATION:}

The analysis of above data concludes that among Group A and B there was a positive change in pre and post values of TUG test in Group A. A positive difference is an indicator of improvement in TUG score whereas negative difference implies decline in the TUG scores.

Table 6: Mean Difference of CTSIB-M Scores Among Group A And Group B

\begin{tabular}{|c|c|c|c|c|c|}
\hline \multicolumn{5}{|c|}{ CTSIB-M TEST } \\
\hline \multicolumn{2}{|c|}{ GROUP A } & \multicolumn{2}{|c|}{ GROUP B } & SIGNIFICANCE & INFERENCE \\
\hline $\begin{array}{c}\text { MEAN } \\
\text { DIFFERENCE }\end{array}$ & SD & $\begin{array}{c}\text { MEAN } \\
\text { DIFFERENCE }\end{array}$ & SD & P VALUE & \\
\hline 5.89 & 8.49 & 0.79 & 2.6 & 0.015 & $\begin{array}{c}\text { HIGHLY } \\
\text { SIGNIFICANT }\end{array}$ \\
\hline
\end{tabular}

Graph 6: Group A V/S Group B Mean Difference of CTSIB-M Scores

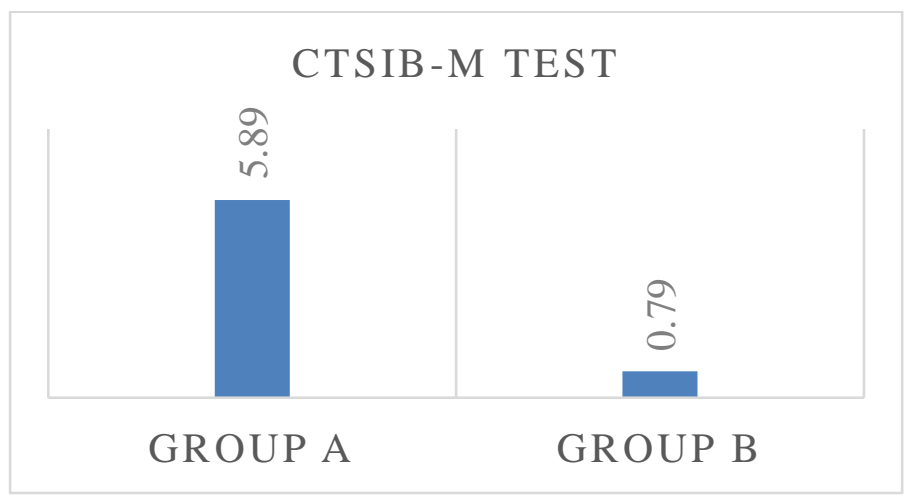

\section{INTERPRETATION:}

The analysis of above data concludes that among Group A and B there was a significant increase in the CTSIBM scores in Group A as opposed to Group B.

\section{IV.DISCUSSION}

The primary goal of the study was to evaluate the effect of 4 week yoga therapy program on balance in geriatric population with mean age of $65.15 \pm 4.2$ in group A (yoga therapy group) and $67.75 \pm 5.7$ years in group B (control group).
The outcome measures analyzed were TUG test and CTSIB-M test.

Statistically significant results were obtained in balance measured by TUG ( $\mathrm{p}$ value $<0.05$ ) and CTSIB-M ( $\mathrm{p}$ value $<0.05$ ) among the subjects in 
yoga therapy group to those who weren't given any intervention.

The decrease in TUG score among Group A is supported by Mary L et al., $2012{ }^{(17)}$ who evaluated the effects of modified chair-yoga in 16 elderly and found improvement in functional mobility by reduction in TUG score.

The improvements in physical measures like balance, directly related to the yoga intervention are not surprising. ${ }^{(18,19)}$ Yoga poses are very similar to conventional balancing exercises given in routine clinical practice. Asanas or poses in the present study are given in different position like sitting and standing in a sequential order and progression was done according to improvement in balance. It ranges from low COM and wide BOS in sitting position to high COM and narrow BOS in standing position.

According to Jayasinghe S R, 2004, ${ }^{(20)}$ yoga practice will lead to improvement in flexibility, balance, strength and overall fitness. Pranayam component of yoga (slow breathing) is able to improve heart rate variability by improving cardiovascular rhythms.

The increase in TUG score among Group B is supported by Camila Tomicki et al., 2016 (21) who assessed the effect of physical exercise program on the balance and risk of falls of institutionalized elderly persons and found negative results with a reduction in body balance and an increased risk of falls after the three months of the study among G1 (control) group of the study.

In addition to the above research article, exposure to cold weather may also result in clinically relevant differences in balance as it leads to reduced muscle power and is related to mobility limitation and decreased functional performance. Indeed, poor explosive power performance may be more indicative of falls risk than traditional strength measurements in older people.

A study by Ulrich Lindemann et al. (2014) concludes the physical performance in older women is reduced in a cold environment. Furthermore, walk-ratio, which was also negatively affected by the cold environment, has also been shown to be associated with risk of falling. ${ }^{(22)}$

Another positive result of the present study was the improvement in the CTSIB-M scores among Group A. Carter et al.,2003 ${ }^{(23)}$ obtained an improvement in static balance using muscular strength training rather than balance training, though only in $6.3 \%$ of the patients. Thus, the present findings suggest that yogasanas leads to more evident positive results in static balance than does muscular strength training.

In his study Mangesh A. Bankar et al.2013 ${ }^{(24)}$ stated yoga exercises involve stretching and relaxing of muscles causing significant physical and mental exertion resulting in benefits like improved muscular strength and muscle mass which results in increased exercise capacity. Yoga exercises improve joint flexibility, prevent decline in the physical function, and improve the QOL of elderly people.

Similar results have been obtained in a study by Goncalves et al., in which data were collected from 83 elderly Yoga practitioners aged 60 years and above. Researchers found that joint flexibility measured using goniometry was significantly more than the control group, also significant reductions in activity execution timings were noted in LatinAmerican development to the maturity Group (LADEG) autonomy protocol. ${ }^{(25)}$ 


\section{v. CONCLUSION}

The study conducted concludes that yogasanas are effective in improving balance in elderly individuals at the end of four weeks compared to control group. Thus it can be used clinically to improve balance in geriatric population.

\section{REFERENCES}

[1]. Singh PK, Kumar L, and CM, Reddy PK. Psychiatric Morbidity in Geriatric Population in Old Age Homes and Community: A Comparative Study. Indian J Psychol Med. 2012 Jan-Mar; 34(1): 39-43.

[2]. Berg K. Balance and its measure in elderly: a review. Physiotherapy Canada. 1989b; 41(5):204-5.

[3]. Barnett A, Smith B, Lord S, Williams M, Baumand A: Community-based group exercise improves balance and reduces falls in at-risk older people: a randomized controlled trial. Age Ageing 2003; 32:407-414.

[4]. Sterling M, Jull G, Wright A. The effect ofmusculoskeletal pain on motor activity andcontrol. J Pain2001; 2(3):135 45.

[5]. Sinaki M, Brey RH, Hughes CA, Larson DR, Kaufman KR (2005) Balance disorder and increased risk of falls in osteoporosis and kyphosis: significance of kyphotic posture and muscle strength. Osteoporos Int 16:1004-1010

[6]. Silsupadol P, Siu KC, Shumway-Cook A, Woollacott MH (2006) Training balance under single and dual-task conditions in older adults with balance impairment. Phys Ther 86:269281

[7]. Maki BE, Mcllroy WE. Postural control in the older adult. Clin Geriatr Med. 1996; 12(4):63558.
[8]. Villa-Forte A. Effects of aging on the musculoskeletal system. Last Full Review/Revision July 2014; 2015

[9]. McGowen J, Raisz L, Noonan A, Elderkin A. Bone health and osteoporosis: A report of the surgeon general. US Dep. Health Hum. Serv; 2004. pp. 69-87

[10]. Shilpa Amarya*, Kalyani Singh and Manisha Sabharwal Ageing Process and Physiological Changes. Lady Irwin College, University of Delhi, New Delhi, India, 2018 pg 8

[11]. Fell J,Williams AD. The effect of aging on skeletal-muscle recovery from exercise: Possible implications for aging athletes. Journal of Aging and Physical Activity. 2008;16(1):97

[12]. Williams GN, Higgins MJ, Lewek MD. Aging skeletal muscle: Physiologic changes and the effects of training. Physical Therapy. 2002;82(1):62-68

[13]. Randomised, controlled, six- month trial of yoga in Healthy seniors: Effects on cognition and quality of life Barry S. Oken, MD et al 2006 pg 2

[14]. Tran MD, Holly RG, Lashbrook J, and Amsterdam EA. Effects of hatha yoga practice on the health-related aspects of physical fitness. Preventive Cardiology. 2001; 4(4):165-170.

[15]. Iyengar BKS. Light on Yoga. 2nd ed. New York: Schocken Books, 1976.

[16]. Falls in Indian older adults: a barrier to active ageing ,SA Dsouza1, PhD, B Rajashekar2, PhD, HS Dsouza3, PhD, KB Kumar4, PhD Asian J Gerontol Geriatr 2014; 9: 33-40

[17]. Galantino ML, Green L, DeCesari JA, MacKain NA, Rinaldi SM, Stevens ME, Wurst VR, Marsico R, Nell M, Mao JJ. Safety and feasibility of modified chairyoga on functional outcome among elderly at risk for falls. International journal of yoga 2012; 5(2):146150. 
[18]. Van Puymbroeck M, Payne LL, Hsieh PC. A phase I feasibility study of yoga on the physical health and coping of informal caregivers. Evidence Based Complement Altern Med 2007;4:519 29

[19]. Arpita. Physiological and psychological effects of Hatha yoga: A review of the literature. The Journal of the International Association of Yoga Therapists, 1990, 1(I\&II) 1-28.

[20]. Jayasinghe SR. Yoga in cardiac health a review.European journal of cardiovascular prevention and rehabilitation, 2004; 11(5):36975.

[21]. Camila Tomicki1, Sheila Cristina Cecagno Zanini1, Luana Cecchin2, Tania Rosane Bertoldo Benedetti3, Marilene Rodrigues Portella1, Camila Pereira Leguisamo1. Effect of physical exercise program on the balance and risk of falls of institutionalized elderly persons: a randomized clinical trial. Rev. Bras. Geriatr. Gerontol., Rio de Janeiro, 2016; 19(3):473-482

[22]. Effect of cold indoor environment on physical performance of older women living in the community ,ULRICH LINDEMANN1, JUHAOKSA2, DAWN A. SKELTON3, NINA BEYER4, JOCHEN KLENK1,5, JULIA ZSCHEILE1, CLEMENS BECKER1, Age and Ageing 2014; 43: 571-575 doi: 10.1093/ageing/afu057

[23]. Carter ND, Khan KM, McKay HA, Petit MA, Waterman C, Heinonen A et al (2002) Community-based exercise program reduces risk factors for falls in 65- to 75-year-old women with osteoporosis: randomized controlled trial. CMAJ 167:997-1004. Erratum in: CMAJ 2003 168:152

[24]. Mangesh A. Bankar, Sarika K. Chaudhari1, Kiran D. Chaudhari2.Impact of long term Yoga practice on sleep quality and quality of life in the elderly.Journal of Ayurveda \& Integrative Medicine | January-March 2013 | Vol 4 | Issue 1 [25]. Gonçalves LC, Vale RG, Barata NJ, Varejão RV, Dantas EH. Flexibility, functional autonomy and quality of life (QoL) in elderly yoga practitioners. Arch Gerontol Geriatr 2011;53:158-62.

\section{Cite this article as :}

Krishna Ketan Patel, Dr. Mayura Deshmukh, Dr. Tushar Palekar, "Effect of Yoga on Balance in Geriatric Population", International Journal of Scientific Research in Science and Technology (IJSRST), Online ISSN : 2395-602X, Print ISSN : 2395-6011, Volume 6 Issue 2, pp. 595-605, MarchApril 2019. Available at doi : https://doi.org/10.32628/IJSRST11962130 Journal URL : http://ijsrst.com/IJSRST11962130 